\title{
PI3K/AKT/mTOR signalling pathway involvement in renal cell carcinoma pathogenesis (Review)
}

\author{
DANIELA MIRICESCU ${ }^{1 *}$, DANIELA GABRIELA BALAN ${ }^{2 *}$, ADRIAN TULIN $^{3,4}$, OVIDIU STIRU $^{5,6}$, \\ ILEANA ADELA VACAROIU ${ }^{7,8}$, DOINA ANDRADA MIHAI ${ }^{9,10}$, CRISTIAN CONSTANTIN POPA ${ }^{11,12}$, \\ RALUCA IOANA PAPACOCEA ${ }^{13}$, MIHALY ENYEDI ${ }^{3,14}$, NEDELEA ANDREI SORIN ${ }^{15}$, GUENADIY VATACHKI ${ }^{16}$, \\ DRAGOȘ EUGEN GEORGESCU ${ }^{11}$, ADRIANA ELENA NICA ${ }^{17}$ and CONSTANTIN STEFANI ${ }^{18^{*}}$
}

${ }^{1}$ Department of Biochemistry, ${ }^{2}$ Discipline of Physiology, Faculty of Dental Medicine; ${ }^{3}$ Department of Anatomy,

Faculty of Medicine, 'Carol Davila' University of Medicine and Pharmacy, 020021 Bucharest;

${ }^{4}$ Department of General Surgery, 'Prof. Dr. Agrippa Ionescu' Clinical Emergency Hospital, 011356 Bucharest;

${ }^{5}$ Department of Cardiovascular Surgery, Faculty of Medicine, 'Carol Davila' University of Medicine and Pharmacy,

020021 Bucharest; ${ }^{6}$ Department of Cardiovascular Surgery, 'Prof. Dr. C. C. Iliescu' Emergency Institute for

Cardiovascular Diseases, 022322 Bucharest; ${ }^{7}$ Department of Nephrology and Dialysis, 'Sf. Ioan’ Emergency Clinical Hospital,

042122 Bucharest; ${ }^{8}$ Department of Nephrology, ${ }^{9}$ Discipline of Diabetes, Nutrition and Metabolic Diseases,

Faculty of Medicine, 'Carol Davila' University of Medicine and Pharmacy, 020021 Bucharest; ${ }^{10}$ Department II of Diabetes,

'Prof. N. Paulescu' Nutrition and Metabolic Diseases National Institute of Diabetes, 020474 Bucharest;

${ }^{11}$ Department of Surgery, Faculty of Medicine, 'Carol Davila' University of Medicine and Pharmacy, 020021 Bucharest;

${ }^{12}$ Department of Surgery, Emergency University Hospital, 050098 Bucharest; ${ }^{13}$ Discipline of Physiology,

Faculty of Medicine, 'Carol Davila' University of Medicine and Pharmacy, 020021 Bucharest;

${ }^{14}$ Department of Radiology, 'Victor Babes' Private Medical Clinic, 030303 Bucharest; ${ }^{15}$ Division of Urology,

'Prof. Dr. Agrippa Ionescu' Clinical Emergency Hospital, 011356 Bucharest; ${ }^{16}$ Department of General Surgery,

'Fundeni' Clinical Institute 022328 Bucharest; ${ }^{17}$ Department of Orthopedics, Anesthesia Intensive Care Unit,

Faculty of Medicine, 'Carol Davila' University of Medicine and Pharmacy, 020021 Bucharest;

${ }^{18}$ Department of Family Medicine and Clinical Base,

Dr. Carol Davila Central Military Emergency University Hospital, 010825 Bucharest, Romania

Received December 16, 2020; Accepted January 15, 2021

DOI: $10.3892 /$ etm.2021.9972

\begin{abstract}
Renal cell carcinoma (RCC) accounts for over $90 \%$ of all renal malignancies, and mainly affects the male population. Obesity and smoking are involved in the pathogenesis of several systemic cancers including RCC. The phosphoinositide 3-kinase (PI3K)/protein kinase $\mathrm{B}(\mathrm{AKT}) / \mathrm{mammalian}$ target of rapamycin (mTOR) signalling pathway regulates cell growth, differentiation, migration, survival, angiogenesis, and metabolism. Growth
\end{abstract}

Correspondence to: Dr Daniela Gabriela Balan, Discipline of Physiology, Faculty of Dental Medicine, 'Carol Davila' University of Medicine and Pharmacy, 37 Dionisie Lupu Street, 020021 Bucharest, Romania

E-mail: gdaniela.balan@yahoo.com

*Contributed equally

Key words: renal cell carcinoma, signalling pathway, risk factors, hyperactivation, tumour progression, mTOR inhibitors factors, hormones, cytokine and many extracellular cues activate PI3K/AKT/mTOR. Dysregulation of this molecular pathway is frequently reported in human cancers including $\mathrm{RCC}$ and is associated with aggressive development and poor survival rate. mTOR is the master regulator of cell metabolism and growth, and is activated in many pathological processes such as tumour formation, insulin resistance and angiogenesis. mTOR inhibitors are used at present as drug therapy for RCC to inhibit cell proliferation, growth, survival, and the cell cycle. Temsirolimus and everolimus are two mTOR inhibitors that are currently used for the treatment of RCC. Drugs targeting the PI3K/AKT/mTOR signalling pathway may be one of the best therapeutic options for RCC.

\section{Contents}

1. Introduction

2. PI3K/AKT signalling pathway: Roles, activation, and isoforms

3. Structure and function of the mTOR pathway

4. PI3K/AKT/mTOR in RCC

5. mTOR inhibitors in RCC

6. Conclusions 


\section{Introduction}

In 2012, 143,000 deaths caused by kidney cancer were reported worldwide, with an increased incidence in the Czech Republic, followed by Eastern and Northern Europe, North America and Australia. Africa and South-East Asia had the lowest mortality rates from kidney cancer. RCC accounts for over $90 \%$ of all renal malignancies and is characterized histologically by the presence of three cell types: $70 \%$ clear cells, between 10 and $15 \%$ papillary cells, and only 5\% chromophobe cells $(1,2)$. The incidence and mortality of renal cell carcinoma (RCC) in the Czech Republic are among the highest in the world with 27.14 new cases and 11.13 deaths per 100,000 persons per year, while in men, the incidence is $63 \%$, with $40 \%$ of cases diagnosed at the advanced or metastatic stage (3).

According to Globocan, in 2018, 403,000 cases of RCC were diagnosed, representing $2.2 \%$ of all cancer cases, with 254,000 cases among men and 148,000 among women. In developed countries, the risk of kidney cancer is $0.69 \%$ in men and $0.35 \%$ in women. In the USA, in 2019, according to published statistics, 74,000 new cases of RCC were reported, representing $4.2 \%$ of all cancers (4). Unfortunately, the RCC incidence rate doubled in 2016, being 14.9/100,000 inhabitants, compared to 1975 , when the incidence was 7.1/100.00 (4).

In Romania, in 2018, in accordance with results published by Globocan, kidney cancer ranked 12th out of all cancers, representing $2.4 \%$, with a mortality risk of $1.8 \%$ and a 5 -year survival rate of $2.878 \%$ (5). Chronic kidney disease (CKD) and diabetic nephropathy represent other renal pathologies among the adult population worldwide (6-9). The leading cause of death among patients with CKD are cardiovascular diseases, which can be associated with vascular calcification (10-12). Uric acid is a biomarker for the cardiovascular risk, hyperuricemia being associated with endothelial dysfunction, inflammation, and the activation of the renin-angiotensin-aldosterone system (13-15).

Smoking is a risk factor for the development of RCC, the risk increasing by $50 \%$ for male smokers, while for female smokers there is an increase of $20 \%$. Obesity is another risk factor for RCC, and a body mass index of $5 \mathrm{~kg} / \mathrm{m}^{2}$ increases the risk by $24 \%$ for men and $34 \%$ for women (1). Hypertension increases the risk of kidney cancer, affecting the renal glomeruli and tubular apparatus $(4,7)$. In addition, a higher rate of hypertension is reported for CKD patients $(16,17)$. Moreover, male sex, an increased BMI and smoking represent a few risk factors for diabetic nephropathy (18). In the pathogenesis of $\mathrm{RCC}$, in addition to histological characterization, a molecular evaluation is required, which can provide crucial information for future therapeutic targets. The phosphoinositide 3-kinase $(\mathrm{PI} 3 \mathrm{~K}) /$ protein kinase $\mathrm{B}(\mathrm{AKT}) / \mathrm{mammalian}$ target of rapamycin (mTOR) signalling pathway is dysregulated in systemic cancers, including RCC. Hyper-activation of this molecular pathway is correlated with aggressive behaviour of RCC tumours and poor patient prognosis $(19,20)$.

\section{PI3K/AKT signalling pathway: Roles, activation, and isoforms}

The PI3K/AKT/mTOR, signalling pathway plays a pivotal role in cell survival and growth, being frequently disrupted in malignant pathologies. A frequent enhanced activity of the
$\mathrm{PI} 3 \mathrm{~K} / \mathrm{AKT} / \mathrm{mTOR}$ pathway in malignant cells is observed, thus the inhibition of mTOR is an attractive strategy to treat cancer (21-29).

Phosphatidylinositol 3-kinases (PI3Ks) are a family of lipid kinases. PI3Ks phosphorylate a component of the eukaryotic cell membrane, namely phosphatidylinositol. Three classes of PI3K (I, II and III) have been identified to date, based on differences in sequence homology and lipid substrate preference (30). Growth factors, cytokines, and hormones bind to receptor tyrosine kinases (RTKs) and G-protein-coupled receptors (GPCRs) and activate PI3K. On the intracellular membrane, class I PI3K phosphorylates the substrate phosphatidylinositol 4,5-bisphosphate $\left(\mathrm{PIP}_{2}\right)$ which transforms into phosphatidylinositol 3,4,5-triphosphate (PIP3), recruiting signalling proteins such as AKT $(31,32)$. All activated PI3K classes are involved in a diversity of cellular processes such as proliferation, survival, metabolism, trafficking, and immunity (33). Phosphatase and tensin homologue (PTEN), the main negative regulator of PI3K, dephosphorylates PIP $_{3}$ into $\mathrm{PIP}_{2}$ (34). AKT is activated by two phosphorylation processes. Phosphoinositide-dependent-protein kinase 1 (PDK1) phosphorylates AKT1 at threonine 308, and the second phosphorylation takes place at serine 473 by mTOR complex $2(35,36)$. Based on differences in serine/threonine residues, AKT is divided into three isoforms (AKT1, AKT2 and AKT3). AKT1 is ubiquitously present in tissues, being involved in cell growth and survival. AKT2 is present mainly in muscle and adipocytes and contributes to glucose homeostasis, while AKT3 is found in the brain and testes. All three isoforms share more than $80 \%$ homology, contain pleckstrin homology $(\mathrm{PH})$, catalytic and regulatory domains and have common specific functions (Fig. 1) (37-41).

\section{Structure and function of the mTOR pathway}

mTOR is a component of the AKT signalling pathway, which promotes cell growth and proliferation in eukaryotic cells $(42,43)$.

mTOR is a central regulator of cell metabolism, proliferation, growth, and survival. This protein kinase is activated in various pathological cellular processes such as tumour formation, angiogenesis, adipogenesis, insulin resistance and activation of T lymphocytes (42-45). Overexpression of mTOR signalling pathway has been observed in various systemic pathologies such as type 2 diabetes and multiple neoplasms including RCC (42-45). mTOR protein is a serine threonine kinase belonging to the PI3K kinase family, which exists in two distinct multi-protein complexes: mTOR1 and mTOR2 (46).

Both complexes have certain common protein components: mTOR (serine/threonine kinase), mLST8 (lethal mammalian with sec-13 protein 8) and DEPTOR (DEP-domain containing mTOR-interacting protein). The mTORC1 complex additionally contains scaffold protein Raptor (regulatory-associated protein of TOR) and AKT substrate protein PRAS40 (proline-rich AKT substrate 40-kDa) (47,48). Scaffold protein Rictor (rapamycin insensitive companion of mTOR), mSIN1 (stress-activated protein kinase-interacting protein 1) and protein associated with Rictor 1 and 2, named PROTOR1, represent the core components of the mTORC2 complex (Fig. 2) $(47,48)$. 


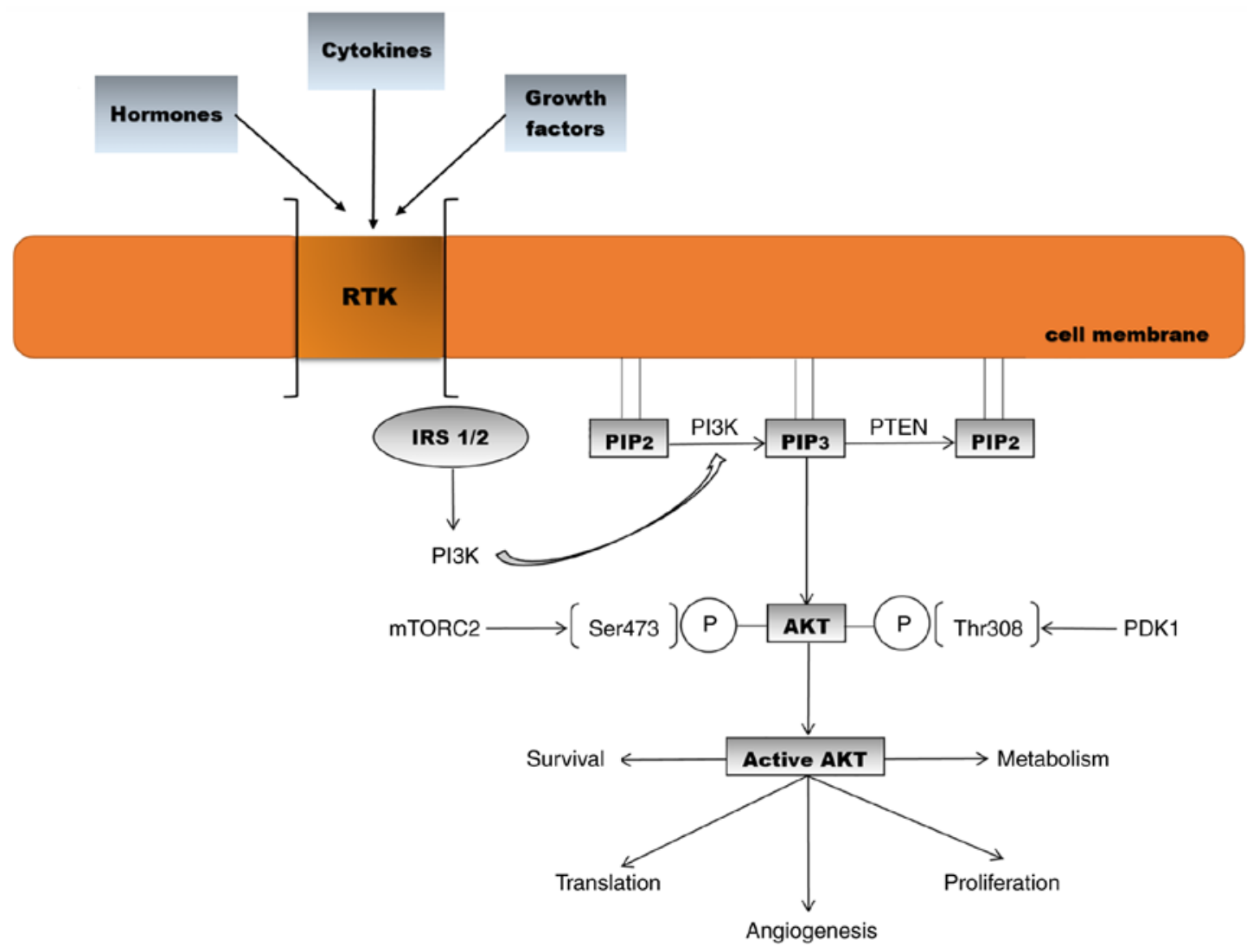

Figure 1. Activation of the AKT signalling pathway and biological effects [adapted from Araki et al (2003) and Meric-Bernstam and Gonzalez-Angulo (2009) $(32,42)]$.RTK, receptortyrosine kinase; IRS, insulin receptor substrate; PIP $_{2}$, phosphatidylinositol 4,5-bisphosphate; PIP $_{3}$, phosphatidylinositol 3,4,5-triphosphate; PTEN, phosphatase and tensin homologue; PI3K, phosphoinositide 3-kinase; AKT, protein kinase B; PDK1, phosphoinositide-dependent-protein kinase 1; mTORC2. mammalian target of rapamycin complex 2.

In response to environmental factors such as amino acids, stress and growth factors, mTORC1 maintains a cellular balance between catabolism and anabolism. Several growth factors such as insulin, insulin-like growth factor (IGF) and amino acids activate mTORC1 through signalling PI3K/AKT-Tuberous sclerosis complex 1/2 (TSC1/2)-RHEB. PI3K-AKT pathway phosphorylates and inhibits TSC1, which causes RHEB (the small GTPase Ras homologue enrich in brain) activation, which represents the GTPase-activating protein $(47,48)$. Hypoxia and DNA damage, are also signals for mTORC1 activation through TSC1/2 $(48,49)$.

mTORC1 activation promotes protein synthesis by ribosome biogenesis and mRNA translation. Ribosomal S6 kinase (S6K) and the inhibitory Eif4e-binding proteins (4E-BPs) are the major downstream effectors of mTORC1, activated by phosphorylation, which will further phosphorylate other substrata, such as ribosomal protein $\mathrm{S} 6$, and protein synthesis initiation factor $4 \mathrm{~B}$ (eIF4B) $(47,50,51)$. mTORC1 regulates cell growth and proliferation, through its downstream effectors, S6K and 4E-BP, in response to IGF, amino acids, hypoxia and DNA damage $(50,52)$. Overexpression of eIF4E is implicated in malignant transformation of some specific cells $(53,54)$. mTORC1 promotes synthesis of purine nucleotides, de novo lipogenesis. Moreover, mTORC1 stimulates glycolysis and glucose uptake through transcription factor hypoxia-inducible factor $\alpha$ (HIF $\alpha)(55,56)$.

mTORC1 is implicated in autophagy-lysosome and ubiquitin-proteasome pathways, involved in protein and organelle turnover. In the nutrient state, ULK1, the mammalian autophagy-initiating kinase is phosphorylated by mTORC1, leading to its inhibition, which further blocks autophagy. Adenosine 5'-monophosphate (AMP)-activated protein kinase (AMPK) activates ULK1 $(57,58)$. mTORC1 activation suppresses the transcription factor EB (TFEB), the most important regulator of the lysosome pathway. mTORC1 inactivation and nutrient deprivation activate TBEB, then its nuclear translocation takes place, leading further to lysosomal and autophagic genes expression (59). Zhao et al and Rousseau and Bertolotti report that the ubiquitin proteasome system (UPS) is increased when mTORC1 is inactivated in mammalian cells $(60,61)$. Moreover, mTORC1 controls the translation of cyclin D, c-Myc, and other key proteins involved in cell proliferation (62). Insulin and IGF activate the mTORC2 signalling pathway. The downstream substrata for this kinase protein are less known. Once activated, mTORC2 phosphorylates members of the AGC kinase family, AKT, SGK and PKC $\alpha$, which are involved in cellular survival, metabolism, and cytoskeletal remodelling. AKT is the most well characterized substratum for mTORC2, being phosphorylated at serine $473(41,63)$. Furthermore, AKT phosphorylates TSC2, which is the upstream inhibitor for mTORC1 $(41,63)$. mTOR may be activated by cAMP-dependent protein kinase (AMP kinase), and TSC1/2. In nutrient and energy depletion states, cAMP and TSC $1 / 2$ suppress mTOR (64). 


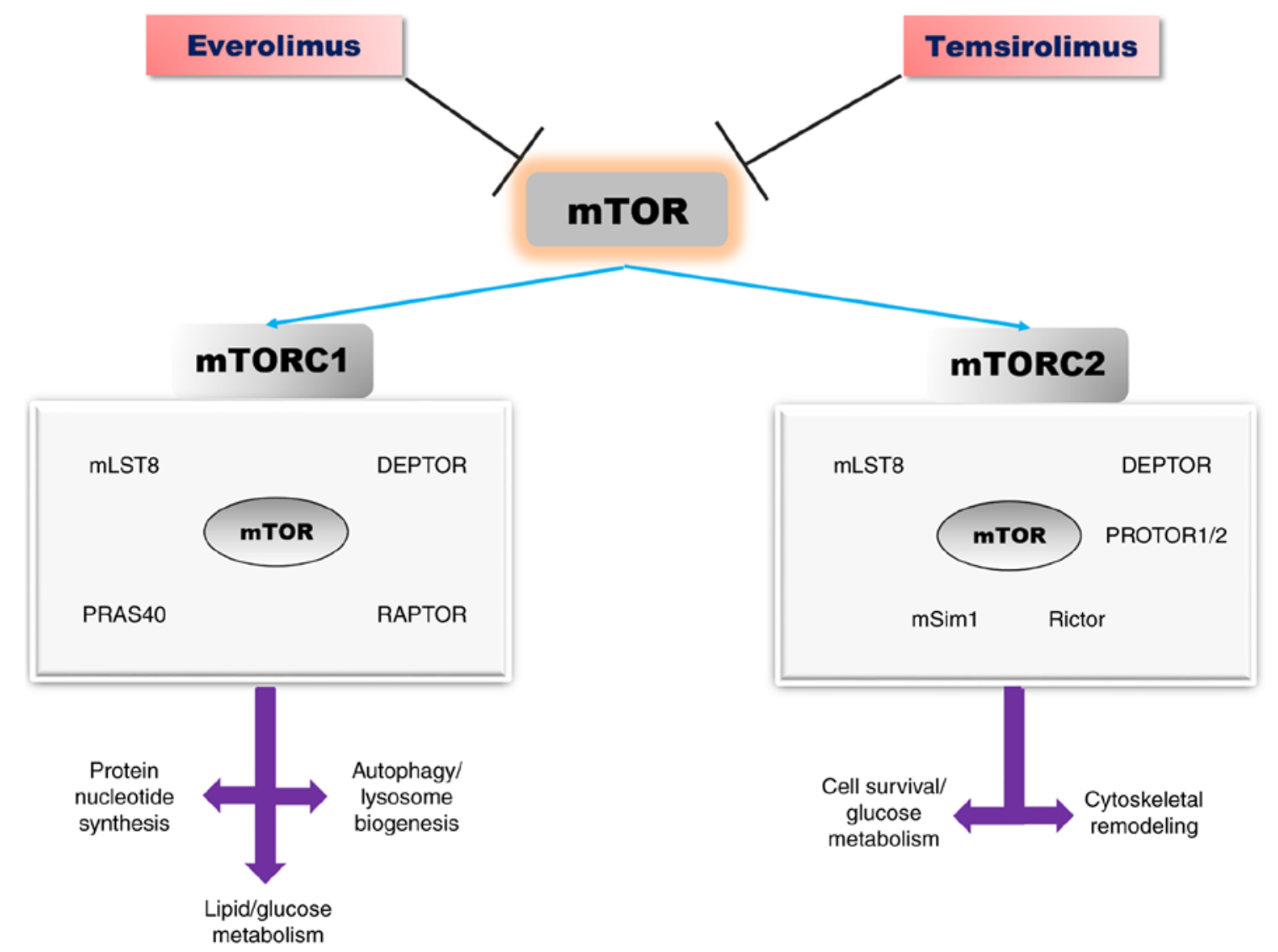

Figure 2. The mTOR signalling pathway: Structure, biological effects, and inhibitors [adapted from Saxton and Sabatini (2017) and Laplante and Sabatin (2012) $(47,48)]$. mTOR, mammalian target of rapamycin; DEPTOR, DEP-domain containing mTOR-interacting protein; PRAS40, proline-rich AKT substrate 40-kDa; mLST8, lethal mammalian with sec-13 protein 8; Raptor, regulatory-associated protein of TOR; Rictor, rapamycin insensitive companion of mTOR; mSIN1, stress-activated protein kinase-interacting protein 1.

\section{PI3K/AKT/mTOR in RCC}

In endothelial cells, there are RTKs to which vascular endothelial growth factor (VEGF) binds (VEGFR1/R2), promoting cell proliferation and migration, by activating the mitogen-activated protein kinases (MAPK) and PI3K/AKT/mTOR signalling pathways (65). Receptors for growth factors, such as VEGF, IGF, epidermal growth factor (EGF), have been identified at the level of clear cell RCC (65). Overexpression of EGF, transforming growth factor (TGF)- $\beta$, and IGF leads to RTK activation, which further activates various signalling pathways, such as RAS/mitogen-activated protein (MEK)/extracellular signal-regulated kinases (ERK) or PI3K/AKT/mTOR, leading to the production of hypoxia-inducible factor (HIF)- $\alpha$, which promotes tumour progression (65). Genetic alterations may activate mTOR, reduce the function of PTEN, which cause abnormal activation of AKT, by increasing the function of the catalytic subunit of PI3K (41,65-67). Sato et al report mutations in the AKT/mTOR signalling pathway in clear cell RCC (68). In RCC tumours, PI3K/AKT/mTOR signalling pathway activation is correlated with aggressive development and poor survival rate $(69,70)$.

Hyperactivity of mTOR may occur through several mechanisms: Over-activation of growth factors, mutations of the PI3K/AKT signalling pathway, decreased expression of TSC1/2, epigenetic suppression of PTEN and Von Hippel-Lindau $(V H L)$ gene inactivation $(65,71)$. Activation of mTOR leads to increased angiogenesis in neighbouring endothelial cells $(65,71)$. In cancer cells, mTOR regulates mRNA translation for HIF1- $\alpha$, HIF- $2 \alpha$ and p70S6 kinase. In the pathogenesis of RCC, overexpression of HIF- $1 \alpha$ and HIF- $2 \alpha$, appears to play an important role, together with overexpression of p70S6K $(65,72-75)$. mTOR is involved in upregulation of HIF- $\alpha$ subunits, while VEGF and other molecules increase angiogenesis $(65,76)$. RCC is characterized by alterations of the $V H L$ gene. The loss of $V H L$ function leads to the deregulation of cyclin D1, a cyclin-dependent kinase cofactor important for cell cycle progression $(65,77,78)$. In clear cell RCC tumorigenesis, the accumulation of HIF-1 $\alpha$ and HIF- $2 \alpha$ represents a critical step, as a result of bi-allelic alteration of the $V H L$ gene. In the presence of phospholipase $\mathrm{D}, \mathrm{mTOR}$ enhances the expression of HIF- $1 \alpha$ and HIF- $2 \alpha$, at the translational level rather than transcriptional $(65,79)$. Chen et al identified the activation of the PI3K/AKT/mTOR signalling pathway in the tissues and cells of patients with RCC. The study reports that inhibition of this pathway may reduce epithelial to mesenchymal cell transition in RCC (21). In 2013, Sato and colleagues published the results of integrated molecular analyses in over 100 cases of clear cell RCC, analysing whole-genome and/or whole-exome and RNA sequencing. VHL gene defect, HIF accumulation, mutations in the PI3K/AKT/mTOR signalling pathway, p53 and DNA methylation were identified in patients with clear cell RCC genetic lesions (68). 


\section{5. mTOR inhibitors in RCC}

To date, three methods have been proposed for developing therapeutic agents for RCC: VEGF, RTK and mTOR inhibitors. The mechanism of action of rapamycin drug analogs includes both angiogenesis and tumour cell proliferation. Drug resistance may reduce the utility of mTOR inhibitors (80). Temsirolimus and everolimus are two mTOR inhibitors, which are currently utilized for the treatment of certain RCC subtypes (19,81-84). In May 2007, FDA approved temsirolimus as treatment in a phase III trial, which included 626 patients with poor-prognostic metastatic RCC. The patients received temsirolimus $(25 \mathrm{mg}$ intravenous weekly), interferon (IFN)- $\gamma\left(3 \times 10^{6} \mathrm{U}\right.$ subcutaneously three-times weekly) or a combination of both (temsirolimus $15 \mathrm{mg}$ weekly and $63 \times 10^{6} \mathrm{U}$ of IFN- $\gamma$ three-times weekly). The survival rate of patients with metastasis RCC treated with temsirolimus was statistically prolonged when compared with patients who received only IFN $-\gamma(\mathrm{P}=0.0069$; hazard ratio, $\mathrm{HR}=0.73$ ). The median overall survival time reported in the temsirolimus group was 10.9 months, 7.3 months in the interferon group and 8.4 months in the combination group. Anaemia, nausea, peripheral oedema, rash, asthenia, hyperlipidemia and hyperglycemia were the common adverse effects observed in patients who received temsirolimus treatment. Based on the results, temsirolimus is the best therapeutic option for metastatic RCC patients. However, the survival rate was not improved in the interferon group by temsirolimus addition (85).

In 2018, Park and colleagues published the results of a phase II clinical trial that included 40 non-clear-cell recurrent or metastatic RCC patients, who received axitinib or temsirolimus. The results of the 3-year study reported promising effects for axitinib in terms of progression-free survival and objective response rate, but not for temsirolimus (86).

In 2017, Bedke et al published the results of a study which included patients with metastatic RCC, who received inhibitors for RTK, mTOR and VEGF administered in 3 stages. Axitinib, sorafenib, sunitinib and pozapanib were the RTK inhibitors used in the study, while temsirolimus and everolimus were the inhibitors for mTOR. Sunitinib is the first novel drug, which doubles progression-free survival in patients with metastatic RCC. In the first line of treatment, 626 patients with RCC, divided into three groups-namely, $80 \%$ with clear RCC cells, $20 \%$ with non-clear RCC and $72 \%$ with metastatic RCC, received temsirolimus, INF- $\alpha$ or a combination of the two. Survival rates were higher in patients receiving temsirolimus vs. INF- $\alpha$ (10.9 months compared with 7.4 months). RTK and mTOR inhibitors were administered in the second line therapy, the results being unclear as to the best treatment option. In the third line of treatment, VEGF and mTOR inhibitors (everolimus) were administered, with everolimus showing beneficial effects. Everolimus and temsirolimus reduced S6K1 and 4EBP1 activities and increased the synthesis of HIF1- $\alpha$. These rapamycin analogues inhibit cell proliferation, growth, and survival, blocking the cell cycle in the G1-phase (84). Until 2006, a high dose of interleukin (IL)-2 remained the best therapeutic target for metastatic clear-cell RCC, but the therapy has evolved and currently three therapeutic targets are proposed. They are inhibitors for RTK-VEGF and mTOR, used in phase III trials, which were found to increase the survival rate (87). In RCC, GNE-477 may be a novel and efficacious dual inhibitor for PI3K-mTOR. Ye et al observed, in primary cultured human RCC cells, that GNE-477 inhibited cell growth, viability, proliferation, cell cycle progression, migration, and invasion. GNE-477 inhibited the PI3K-AKT-mTOR signalling pathway in primary RCC cells, by blocking AKT1, p70S6K1, p85 and S6. In vivo studies made on nude mice demonstrated that intraperitoneal injection of GNE-477 suppressed tumour growth. GNE-477 inhibited RCC cell growth in vitro and in vivo (88).

\section{Conclusions}

Obesity, smoking, and hypertension are risk factors for RCC, representing, in 2018,2.2\% of all cancers worldwide, with a higher incidence in men compared with women. The PI3K/AKT/mTOR signalling pathway is involved in protein and nucleotide synthesis, lipid/glucose metabolism, autophagy, translation, angiogenesis, cell survival and proliferation. Over-activation of the PI3K/AKT/mTOR signalling pathway is crucial for RCC cell survival, proliferation, migration, and metastasis.

Drugs or pharmacological inhibitors of this signalling cascade are promising and important targets for RCC. Temsirolimus and everolimus are two mTOR inhibitors that are used for RCC therapy at present, which have been found to increase the patient survival rate.

\section{Acknowledgements}

Not applicable.

\section{Funding}

No funding was received.

\section{Availability of data and materials}

All information provided in this review is documented by relevant references.

\section{Authors' contributions}

DM, DGB, AT, OS, IAV, DAM, CCP, RIP, ME, NAS, GV, DEG, AEN and CS designed the review, performed the literature search, selected the included studies and wrote the manuscript and. DM, DGB, AT, OS, IDV, DAM, CCP, RIP, ME, NAS, GV, DEG, AEN and CS critically revised the manuscript. All authors read and approved the final manuscript. The contributions of all the authors on this review are greatly valued and appreciated.

\section{Ethics approval and consent to participate}

Not applicable.

\section{Patient consent for publication}

Not applicable.

\section{Competing interests}

The authors declare that they have no competing interests. 


\section{References}

1. Znaor A, Lortet-Tieulent J, Laversanne MA, Jemal A and Bray F: International variations and trends in renal cell carcinoma incidence and mortality. Eur Urol 67: 519-530, 2015.

2. Saad AM, Gad MM, Al-Husseini MJ, Ruhban IA, Sonbol MB and Ho TH: Trends in renal-cell carcinoma incidence and mortality in the United States in the last 2 decades: A SEER-based study. Clin Genitourin Cancer 17: 46-57.e5, 2019.

3. Poprach A, Bortlíček Z, Büchler T, Melichar B, Lakomý R, Vyzula R, Brabec P, Svoboda M, Dušek L and Gregor J: Patients with advanced and metastatic renal cell carcinoma treated with targeted therapy in the Czech Republic: Twenty cancer centres, six agents, one database. Med Oncol 29: 3314-3320, 2012.

4. Padala SA, Barsouk A, Thandra KC, Saginala K, Mohammed A Vakiti A, Rawla P and Barsouk A: Epidemiology of renal cell carcinoma. World J Oncol 11: 79-87, 2020

5. World Health Organization: Globocan 2020. Cancer Today. Data visualization tools for exploring the global cancer burden in 2020. https://gco.iarc.fr/today/data/factsheets/popu lations/642-romania-fact-sheets. Accessed August, 2020.

6. Bălan DG, Balcangiu-Stroescu AE, Tănăsescu MD, Diaconescu AC, Răducu L, Mihai A, Tănase M, Stănescu II and Ionescu D Nutritional intervention in patients with diabetic renal disease-a brief presentation. Rev Chim Buchar 69: 4078-4082, 2018.

7. Măndiță A, Timofte D, Balcangiu-Stroescu AE, Bălan DG Răducu L, Tănăsescu MD, Diaconescu AC, Dragos D, Coșconel I and Ionescu D: Treatment of high blood pressure in patients with chronic renal disease. Rev Chim Buchar 70: 993-995, 2019.

8. Totan A, Balcangiu-Stroescu AE, Melescanu Imre M, Miricescu D, Balan DG, Stanescu II, Ionescu D, Timofte D, Tanasescu MD and Greabu M: XOR-possible correlations with oxidative stress and inflammation markers in the context of diabetic kidney disease. Rev Chim Buchar 70: 1396-1398, 2019.

9. Alicic RC, Rooney MT and Tuttle KR: Diabetic kidney disease: Challenges, progress, and possibilities. Clin J Am Soc Nephrol 12: 2032-2045, 2017.

10. Disthabanchong S: Vascular calcification in chronic kidney disease: Pathogenesis and clinical implication. World J Nephrol 6: 43-53, 2012.

11. Timofte D, Ionescu D, Medrihan L, Măndită A, Rășină A and Damian L: Vascular calcification and bone disease in hemodialysis patients assessment, association and risk factors. Nephrology Dialysis Transplantation; Oxford Univ Press 22: 325-326, 2007.

12. Timofte D, Dragos D, Balcangiu-Stroescu A, Tănăsescu M Bălan DG, Răducu L, Tulin A, Stiru O and Ionescu D: Abdominal aortic calcification in predialysis patients: Contribution of traditional and uremia-related risk factors. Exp Ther Med 20: 97-102, 2020.

13. Timofte D, Măndiță A, Balcangiu-Stroescu AE, Bălan DG, Răducu L, Tănăsescu MD, Diaconescu AC, Dorin D, Cosconel CI and Ionescu D: Hyperuricemia and cardiovascular diseases-clinical and paraclinical correlations. Rev Chim Buchar 70: 1045-1046, 2019.

14. Epingeac ME, Gaman MA, Diaconu C, Gad M and Gaman AM: The evaluation of oxidative stress in obesity. Rev Chim Buchar 70: 2241-2244, 2019.

15. Diaconu C: Midaortic syndrome in a young man. Cor et Vasa 59: e171-e173, 2017.

16. Balcangiu-Stroescu AE, Tănăsescu MD, Diaconescu A, Răducu L, Constantin AM,Bălan DG,Tărmure V and Ionescu D: Cardiovascular comorbidities, inflammation and serum albumin levels in a group of hemodialysis patients. Rev Chim Buchar 69: 926-929, 2019.

17. Diaconu C: Treatment of Diabetes in Patients with Heart Failure. The 3rd International Conference on Interdisciplinary Management of Diabetes Mellitus and its Complications-Diabetes Mellitus in Internal Medicine, INTERDIAB 2017 Proceedings. Serafinceanu C, Negoita O and Elian V (eds). Niculescu, Bucharest, pp170-177, 2017.

18. Balcangiu-Stroescu AE, Tănăsescu MD, Diaconescu AC Răducu L, Bălan DG, Mihai A, Tănase M, Stănescu II and Ionescu D: Diabetic nephropathy: A concise assessment of the causes, risk factors and implications in diabetic patients. Rev Chim Buchar 69: 3118-3121, 2018.

19. Husseinzadeh HD and Garcia JA: Therapeutic rationale for mTOR inhibition in advanced renal cell carcinoma. Curr Clin Pharmacol 6: 214-221, 2011.

20. Chen H, Zhu D, Zheng Z, Cai Y, Chen Z and Xie W: CEP55 promotes epithelial-mesenchymal transition in renal cell carcinoma through PI3K/AKT/mTOR pathway. Clin Transl Oncol 21: 939-949, 2019
21. Xiang RF, Wang Y, Zhang N, Xu WB, Cao Y, Tong J, Li JM, Wu YL and Yan H: MK2206 enhances the cytocidal effects of bufalin in multiple myeloma by inhibiting the AKT/mTOR pathway. Cell Death Dis 8: e2776, 2017.

22. Martini M, de Santis MC, Braccini L, Gulluni F and Hirsch E PI3K/AKT signalling pathway and cancer: An updated review. Ann Med 46: 372-383, 2014.

23. Costa RLB, Han HS and Gradishar WJ: Targeting the PI3K/AKT/mTOR pathway in triple-negative breast cancer: A review. Breast Cancer Res Treat 69: 397-406, 2018.

24. Sathe A and Nawroth R: Targeting the PI3K/AKT/mTOR pathway in bladder cancer. Methods Mol Biol 1655: 335-350, 2018.

25. O'Donnell JS, Massi D, Teng MW and Mandala M: PI3K-AKT-mTOR inhibition in cancer immunotherapy, redux. Semin Cancer Biol 48: 91-103, 2018.

26. Chamcheu JC, Roy T, Uddin MB, Banang-Mbeumi S, Chamcheu RN, Walker AL, Liu YY and Huang S: Role and therapeutic targeting of the PI3K/AKT/mTOR signaling pathway in skin cancer: A review of current status and future trends on natural and synthetic Agents therapy. Cells 8: 803, 2019.

27. Bertacchini J, Heidari N, Mediani L, Capitani S, Shahjahani M, Ahmadzadeh A and Saki N: Targeting PI3K/AKT/mTOR network for treatment of leukemia. Cell Mol Life Sci 72: 2337-2347, 2015.

28. Aggarwal S, John S, Sapra L, Sharma SC and Das SN: Targeted disruption of PI3K/AKT/mTOR signaling pathway, via PI3K inhibitors, promotes growth inhibitory effects in oral cancer cells. Cancer Chemother Pharmacol 83: 451-461, 2019.

29. Li Z, Liu J, Que L and Tang X: The immunoregulatory protein B7-H3 promotes aerobic glycolysis in oral squamous carcinoma via PI3K/AKT/mTOR pathway. J Cancer 10: 5770-5784, 2019.

30. Graupera M and Potente M: Regulation of angiogenesis by PI3K signaling networks. Exp Cell Res 319: 1348-1355, 2013.

31. Carnero A, Blanco-Aparicio C, Renner O, Link W and Leal JF: The PTEN/PI3K/AKT signalling pathway in cancer, therapeutic implications. Curr Cancer Drug Targets 8: 187-198, 2008.

32. Fresno Vara JA, Casado E, de Castro J, Cejas P, Belda-Iniesta C and González-Barón M: PI3K/AKT signalling pathway and cancer. Cancer Treat Rev 30: 193-204, 2004.

33. Araki N,Hatae T,Furukawa A and Swanson JA: Phosphoinositide3-kinase independent contractile activities associated with Fcgamma-receptor-mediated phagocytosis and macropinocytosis in macrophages. J Cell Sci 116: 247-257, 2003.

34. Zhang J, Yu XH, Yan YG, Wang C and Wang WJ: PI3K/AKT signaling in osteosarcoma. Clin Chim Acta 444: 182-192, 2015.

35. Regan MM and Phillip AD: AKT-dependent and independent mechanisms of mTOR regulation in cancer. Cell Signal 21: 656-664, 2009

36. Sarbassov DD, Guertin DA, Ali SM and Sabatini DM: Phosphorylation and regulation of AKT/PKB by the rictor-mTOR complex. Science 307: 1098-1101, 2005.

37. Krycer JR, Sharpe LJ, Luu W and Brown AJ: The AKT-SREBP nexus: Cell signaling meets lipid metabolism. Trends Endocrinol Metab 21: 268-276, 2010.

38. Abeyrathna P and Su Y: The critical role of AKT in cardiovascular function. Vascul Pharmacol 74: 38-48, 2015.

39. Nicholson KM and Anderson NG: The protein kinase B/AKT signalling pathway in human malignancy. Cell Signal 14: 381-395, 2002.

40. Brazil DP, Yang ZZ and Hemmings BA: Advances in protein kinase B signalling: AKTion on multiple fronts. Trends Biochem Sci 29: 233-242, 2004.

41. Hers I, Vincent EE and Tavaré JM: AKT signalling in health and disease. Cell Signal 23: 1515-1527, 2011.

42. Meric-Bernstam F and Gonzalez-Angulo AM: Targeting the mTOR signaling network for cancer therapy. J Clin Oncol 27: 2278-2287, 2009

43. JIlha J, Espírito-Santo CC and de Freitas GR: mTOR signaling pathway and protein synthesis: From training to aging and muscle autophagy. Adv Exp Med Bio 1088: 139-151, 2018.

44. Ayuk SM and Abrahamse H: mTOR signaling pathway in cancer targets photodynamic therapy in vitro. Cells 8: 431, 2019.

45. Battelli $C$ and Cho DC: $m$ TOR inhibitors in renal cell carcinoma. Therapy 8: 359-367, 2011.

46. Guertin DA and Sabatini DM: Defining the role of mTOR in cancer. Cancer Cell 12: 9-22, 2007.

47. Saxton RA and Sabatini DM: mTOR signaling in growth, metabolism, and disease. Cell 168: 960-976, 2017.

48. Laplante M and Sabatini DM: mTOR signaling in growth control and disease. Cell 149: 274-293, 2012. 
49. Inoki K, Zhu T and Guan KL: TSC2 mediates cellular energy response to control cell growth and survival. Cell 115: 577-590, 2003.

50. Cornu M, Albert V and Hall MN: mTOR in aging, metabolism, and cancer. Curr Opin Genet Dev 23: 53-62, 2013

51. Stallone G, Infante B, Prisciandaro $C$ and Grandaliano G: mTOR and aging: An old fashioned dress. Int J Mol Sci 20: 2774, 2019.

52. Wullschleger K, Loewith R and Hall EB: TOR signaling in growth and metabolism. Cell 124: 471-484, 2006.

53. Fredrichkson RM, Mushynski WE and Sonenberg N: Phosphorylation of translation initiation factor eIf-4E is induced in a Ras-dependent manner during nerve growth factor-mediated PC 12 cell differentiation. Mol Cell Biol 12: 1239-1247, 1992.

54. Martin CK and Borden KL: The oncogene eIF4E: Using biochemical insights to target cancer. $\mathrm{J}$ Interferon Cytokine Res 33: 227-238, 2013.

55. Ben-Sahra I, Hoxhaj G, Ricoult SJH, Asara JM and Manning BD: mTORC1 induces purine synthesis through control of the mitochondrial tetrahydrofolate cycle. Science 351: 728-733, 2016.

56. Düvel K, Yecies JL, Menon S, Raman P, Lipovsky AI, Souza AL, Triantafellow E, Ma Q, Gorski R, Cleaver S, et al: Activation of a metabolic gene regulatory network downstream of mTOR complex 1. Mol Cell 39: 171-183, 2010.

57. Kim J, Kundu M, Viollet B and Guan KL: AMPK and mTOR regulate autophagy through direct phosphorylation of Ulk1. Nat Cell Biol 13: 132-141, 2011.

58. Tripathi DN, Chowdhury R, Trudel LJ, Tee AR, Slack RS, Walker CL and Wogan GN: Reactive nitrogen species regulate autophagy through ATM-AMPK-TSC2-mediated suppression of mTORC1. Proc Natl Acad Sci USA 110: E2950-E2957, 2013.

59. Settembre C, Zoncu R, Medina DL, Vetrini F, Erdin S, Erdin S, Huynh T, Ferron M, Karsenty G, Vellard MC, et al: A lysosome-to-nucleus signalling mechanism senses and regulates the lysosome via mTOR and TFEB. EMBO J 31: 1095-1108, 2012.

60. Zhao J, Zhai B, Gygi SP and Goldberg AL: mTOR inhibition activates overall protein degradation by the ubiquitin proteasome system as well as by autophagy. Proc Natl Acad Sci USA 112: 15790-15797, 2015.

61. Rousseau A and Bertolotti A: An evolutionarily conserved pathway controls proteasome homeostasis. Nature 536: 184-189, 2016.

62. Fingar DC, Richardson CJ, Tee AR, Cheatham L, Tsou C and Blenis J: mTOR controls cell cycle progression through its cell growth effectors S6K1 and 4EBP1/eukaryotic translation factor 4E. Mol Cell Biol 24: 200-216, 2004.

63. Cai H, Dong LQ and Liu F: Recent advances in adipose mTOR signaling and function: Therapeutic prospects. Trends Pharmacol Sci 37: 303-317, 2016.

64. Inoki K and Guan KL: Complexity of the TOR signaling network. Trends Cell Biol 16: 206-212, 2006.

65. Kumar A, Kumari N, Gupta V and Prasad R: Renal cell carcinoma: Molecular aspects. Ind J Clin Biochem 33: 246-254, 2018

66. Neshat MS, Mellinghoff IK, Tran C, Stiles B, Thomas G, Petersen R, Frost P, Gibbons JJ, Wu H and Sawyers CL: Enhanced sensitivity of PTEN-deficient tumors to inhibition of FRAP/mTOR. Proc Natl Acad Sci USA 98: 10314-10319, 2001

67. Jamaspishvili T, Berman DM, Ross AE, Scher HI, De Marzo AM, Squire JA and Lotan T: Clinical implications of PTEN loss in prostate cancer. Nat Rev Urol 15: 222-234, 2018.

68. Sato Y, Yoshizato T, Shiraishi Y, Maekawa S, Okuno Y, Kamura T, Shimamura T, Sato-Otsubo A, Nagae G, Suzuki H, et al: Integrated molecular analysis of clear-cell renal cell carcinoma. Nat Genet 45: 860-867, 2013.

69. Pantuck AJ, Seligson DB, Klatte T, Yu H, Leppert JT, Moore L, O'Toole T, Gibbons J, Belldegrun AS and Figlin RA: Prognostic relevance of the mTOR pathway in renal cell carcinoma: Implications for molecular patient selection for targeted therapy. Cancer 109: 2257-2267, 2007.

70. Damayanti NP, Budka JA, Khella HWZ, Ferris MW, Ku SY, Kauffman E, Wood AC, Ahmed K, Chintala VN, Adelaiye-Ogala R, et al: Therapeutic targeting of TFE3/IRS-1/ $\mathrm{PI} 3 \mathrm{~K} / \mathrm{mTOR}$ axis in translocation renal cell carcinoma. Clin Cancer Res 24: 5977-5989, 2018.

71. Brugarolas J: Renal-cell carcinoma-molecular pathways and therapies. N Engl J Med 356: 185-187, 2007.
72. Robb VA, Karbowniczek M, Klein-Szanto AJ and Henske EP: Activation of the mTOR signaling pathway in renal clear cell carcinoma. J Urol1 77: 346-352, 2007.

73. Hudson CC, Liu M, Chiang GG, Otterness DM, Loomis DC, KaperF, Giaccia AJ and Abraham RT: Regulation of hypoxia-inducible factor la expression and function by the mammalian target of rapamycin. Mol Cell Biol 22: 7004-7014, 2002.

74. Miikkulainen P, Högel H, Seyednasrollah F, Rantanen K, Elo LL and Jaakkola PM: Hypoxia-inducible factor (HIF)-prolyl hydroxylase 3 (PHD3) maintains high HIF2A mRNA levels in clear cell renal cell carcinoma. J Biol Chem 294: 3760-3771, 2019.

75. Fiorini C, Massari F, Pedron S, Sanavio S, Ciccarese C, Porcaro AB, Artibani W, Bertoldo F, Zampini C, Sava T, et al: Methods to identify molecular expression of mTOR pathway: A Rationale approach to stratify patients affected by clear cell renal cell carcinoma for more likely response to mTOR inhibitors. Am J Cancer Res 4: 907-915, 2014.

76. Pantuck AJ,Zeng G, Belldegrun AS and Figlin RA: Pathobiology, prognosis, and targeted therapy for renal cell carcinoma: Exploiting the hypoxia-induced pathway. Clin Cancer Res 9: 4641-4652, 2003

77. Baba M, Hirai S, Yamada-Okabe H, Hamada K, Tabuchi H, Kobayashi K, Kondo K, Yoshida M, Yamashita A, Kishida T, et al: Loss of von Hippel-Lindau protein causes cell density dependent deregulation of cyclinD1 expression through hypoxia-inducible factor. Oncogene 22: 2728-2738, 2003.

78. Zatyka M, da Silva NF, Clifford SC, Morris MR, Wiesener MS, Eckardt KU, Houlston RS, Richards FM, Latif F and Maher ER: Identification of cyclin D1 and other novel targets for the von Hippel-Lindau tumor suppressor gene by expression array analysis and investigation of cyclin D1 genotype as a modifier in von Hippel-Lindau disease. Cancer Res 62: 3803-3811, 2002.

79. Toschini A, Edelstein J, Rockwell P, Ohh M and Foster DA: HIF alpha expression in HVL-deficient renal cancer cells is dependent on phospholipase D. Oncogene 27: 2746-2753, 2008.

80. Carew JS, Kelly KR and Nawrocki ST: Mechanisms of mTOR inhibitor resistance in cancer therapy. Target Oncol 6: 17-22, 2011.

81. Pal SK and Quinn DI: Differentiating mTOR inhibitors in renal cell carcinoma. Cancer Treat Rev 39: 709-719, 2013.

82. Konings IR, Verweij J, Wiemer EA and Sleijfer S: The applicability of mTOR inhibition in solid tumors. Curr Cancer Drug Targets 9: 439-450, 2009.

83. Motzer RJ,Escudier B, Oudard S, Hutson TE, Porta C, Bracarda S, Grünwald V, Thompson JA, Figlin RA, Hollaender N, et al: Efficacy of everolimus in advanced renal cell carcinoma: A double-blind, randomised, placebo-controlled phase III trial. Lancet 372: 449-56, 2008.

84. Bedke J, Gauler T, Grünwald V, Hegele A, Herrmann E, Hinz S, Janssen J, Schmitz S, Schostak M, Tesch H, et al: Systemic therapy in metastatic renal cell carcinoma. World J Urol 35: 179-188, 2017.

85. Hudes G, Carducci M, Tomczak P, Dutcher J, Figlin R, Kapoor A, Staroslawska E, Sosman J, McDermott D, Bodrogi I, et al: Temsirolimus, interferon alfa, or both for advanced renal-cell carcinoma. N Engl J Med 356: 2271-2281, 2007.

86. Park I, Lee SH and Lee JL: A Multicenter phase II trial of axitinib in patients with recurrent or metastatic non-clear-cell renal cell carcinoma who had failed prior treatment with Temsirolimus. Clin Genitourin Cancer 16: e997-e1002, 2018.

87. Tegos T, Tegos K, Dimitriadou A and Dimitriadis G: Current and emerging first-line systemic therapies in metastatic clear-cell renal cell carcinoma. J BUON 24: 1340-1353, 2019.

88. Ye X, Ruan JW, Huang H, Huang WP, Zhang Y and Zhang F: PI3K-AKT-mTOR inhibition by GNE-477 inhibits renal cell carcinoma cell growth in vitro and in vivo. Aging (Albany NY) 12: 9489-9499, 2020.

This work is licensed under a Creative Commons Attribution-NonCommercial-NoDerivatives 4.0 International (CC BY-NC-ND 4.0) License. 